\title{
Response of Italian Domestic Heating Oil Market to Variations in Crude Oil Costs: Symmetric or Asymmetric?
}

\author{
Fidelia N. Onuigbo ${ }^{1} \quad$ Jonathan E. Ogbuabor $^{2^{*}}$ \\ 1.Department of Economics, Enugu State University of Science and Technology (ESUT), Enugu, Nigeria \\ 2.Department of Economics, University of Nigeria, Nsukka, Nigeria
}

\begin{abstract}
This study examined the Italian domestic heating oil market for evidence of asymmetric price adjustment and rentseeking following changes in crude oil costs. The study adopted the recently developed nonlinear autoregressive distributed lag (NARDL) modeling framework, and used monthly time series data for the period January 2005 to December 2015. The findings reveal that the speed of adjustment was sluggish at $17 \%$ all through, which is typical of markets witnessing irregular behaviours such as collusion and rent-seeking. The results further indicate the presence of short-run additive asymmetry at 5\% level only at pump, which is consistent with the rockets and feathers effect. However, the results did not show any evidence of long-run asymmetry or long-run rent-seeking. Even in the short-run, the results did not reveal any pattern of rent-seeking. Thus, the study concludes that the presence of sluggish speed of adjustment and rockets and feathers effect in the pump prices raise serious anti-trust issues. Accordingly, the study recommends that the market should be continuously monitored so that the dominant status of retailers like the Eni brand is not abused, thereby leading to less competition and collusive behaviours.
\end{abstract}

Keywords: Rockets and Feathers effect; Rent-seeking; Asymmetric Price Adjustment; Nonlinear ARDL model; Italy

JEL Codes: Q43; D40; C22; N94.

DOI: $10.7176 / \mathrm{JETP} / 9-2-02$

\section{Introduction}

Crude oil is the main input material in the production of several petroleum products such as domestic heating oil, automotive diesel, gasoline and industrial fuel oil. Thus, economic expectation is that the retail prices of domestic heating oil should always move in tandem with crude oil costs. In other words, the relationship between crude oil costs and the retail products prices is expected to be symmetric rather than asymmetric. However, available statistics indicate that this is hardly the case. For instance, the monthly oil price statistics of the International Energy Agency (IEA, http//www.iea.org/statistics/topics/pricesandtaxes/), which monitors oil prices and retail petroleum products prices in eight selected economies, indicate that the average cost of imported crude oil in Italy declined by $66 \%$ from 111.59 USD per barrel in June 2014 to 37.6 USD per barrel in December 2015 while the pump price of domestic heating oil declined only marginally by 23\% from 1400.91 Euro per 1000 litres to 1079.14 Euro per 1000 litres over the same period. Interestingly, the statistics also indicate that while crude oil price declined from 41.17 USD per barrel in January 2009 to 37.6 USD per barrel in December 2015, the retail price of domestic heating oil in Italy increased from 1022.02 Euro per 1000 litres to 1079.14 Euro per 1000 litres over the same period.

The above asymmetric pattern of retail price adjustment was the subject of three main investigations by Monopolies and Mergers Commission (MMC) between 1965 and 1990 in the UK gasoline market, which suspected that the market may have been witnessing non-competitive pricing and collusive behavior. The MMC found evidence of asymmetric response of gasoline price to changes in crude oil cost. The MMC termed this pattern of asymmetric adjustment "rockets and feathers", but failed to establish it through econometric work. Rockets and feathers is thus a term used to describe the behavior of retailers who adjust prices upwards very rapidly (i.e. like rockets) following rising input costs but when input costs decline they adjust prices downwards very sluggishly (i.e. like feathers hanging in the air). Bacon (1991) econometrically established the reality of asymmetric price transmission from crude oil market to retail gasoline market as well as the prevalence of the rockets and feathers effect in the retail gasoline market. It is the goal of this study to investigate the Italian domestic heating oil market for evidence of asymmetric price adjustment following changes in crude oil cost. This study also examines the market for evidence of rent-seeking.

Like other European countries discussed above, Italy also has a negligible domestic oil production activity. Its oil import dependency ratio ranged between $92.3 \%$ and $93.1 \%$ since 2005. In 2005 and 2010, it remained at $93.0 \%$, but in 2011 and 2012 , it stood at $93.1 \%$ and $92.3 \%$, respectively. Clearly, this shows that Italy is almost entirely dependent on imports for its oil supply. However, Italy plays an important role as Europe's largest exporter of refined products, providing finished products (gasoline, diesel and residual fuels) to other countries. There are 14 major refineries operating in Italy, 11 of which are located along the coast and are supplied by sea. The other three are situated in the Po Valley, in the north of Italy, and are supplied by pipelines from Genoa, Venice and Vado Ligure. Italian refineries produce a surplus of gasoline, diesel oil and residual fuels; thus, Italy is a net 
exporter of these products. However, it also maintains a deficit in jet and kerosene, liquefied petroleum gas (LPG) and ethane and naphtha, which predisposes these products to asymmetric price adjustment. Though the Italian oil market is fully deregulated, with decisions regarding imports, exports, trade and pricing determined by the industry participants, with regard to the downstream sector, Eni has a dominant status with the largest retail market share of $31.2 \%$ as of 2012. Specifically, it operates 4,780 service stations under the Eni and Agip brands. Such dominant position also predisposes the market to collusion, less competition and other irregular behaviours. Decree "Salva Italia" provides the legal basis for the excise tax rate imposed on retail petroleum products.

\section{An overview of the empirical literature}

Following the initial investigations by the UK Monopolies and Mergers Commission (MMC, 1965, 1979, 1990), several empirical studies have investigated the behavior of firms in markets suspected to be witnessing asymmetric transmission of input costs to retail products prices in such a manner that allows firms to earn temporary excess profits. Some of these studies explain the relationship between retail petroleum products prices and crude oil costs, emphasizing that when firms in the oil industry are confronted by rising input costs (i.e rising crude oil costs), they rapidly adjust retail petroleum product prices upwards, but when the same firms are faced with decreasing crude oil costs, they adjust retail petroleum products downwards very sluggishly.

Bacon (1991) used data from 1982 to 1989 and a quadratic quantity adjustment model to examine the UK retail gasoline market for evidence of the rockets and feathers hypothesis. The results are in support of the hypothesized asymmetry. Manning (1991) used an earlier dataset for the period 1973 to 1988 and found evidence of asymmetry in the UK retail petrol market. Karrenbrock (1991) observed that both oil refiners and retailers may be responsible for the asymmetric adjustment of retail prices to crude oil cost changes. The study then analyzed the role that retailers may play in the perceived asymmetric movement of retail gasoline prices, by testing whether wholesale gasoline price increases in the US are passed along to the retail customer more fully and rapidly than are wholesale gasoline price decreases. The findings indicate that consumers will experience the bulk of a wholesale price change sooner for price increases than they do for decreases. This is consistent with the hypothesized asymmetry. Using data for the period 1986 - 1992 and Error Correction Models, Borenstein Cameron and Gilbert (1992, henceforth BCG) investigated the US retail gasoline market using data for the period 1986 to 1992 to analyze price transmission at different points in the distribution chain. The results show that retail gasoline prices respond more quickly to increases than to decreases in crude oil prices.

Even though Reilly and Witt (1998) used monthly UK data and ECM framework to investigate the retail gasoline market, their findings are consistent with Bacon (1991) and Manning (1991). Balke, Brown and Yucel (1998) extended the work of BCG by using different model specifications following concerns that the periodicity of the data, the sample period of estimation, and the model specification may have affected the results of previous studies. They used weekly data from 1987 through early 1996, and find that most of the price volatility originates upstream. They also find econometric evidence of asymmetry in the extended sample, which are sensitive to model specification but not to sample period. Overall, the results validate the findings of BCG. The monthly data of Swedish gasoline market during 1980 to 1996 was used by Asplund, Erikson and Friberg (2000) to explore the market. They find support for the hypothesized asymmetry that the retail price is stickier downwards than upwards in response to oil cost shocks. Chacra (2002) examined the effects of global energy prices in Canada especially the response of the consumer price indexes for gasoline, heating oil, natural gas, and electricity to movements in world crude oil prices, using an error correction framework. The results indicate that the forecasting ability of the error-correction models outperform that of competing autoregressive and random-walk models. Also the study finds that though prices at the retail level are determined by input costs, industry dynamics, and in some cases, by government regulation: the adjustment process of downstream prices indicate that government regulation leads to a sluggish adjustment process, as seen in the retail natural gas and electricity markets. These findings are consistent with the hypothesized asymmetry.

In a study that explored the degree of competition in various gasoline markets, Polemis and Fotis (2014) inferred possible causes of price asymmetry across the globe. They used the Dynamic ordinary least square method in order to estimate price asymmetry in twelve European countries and the United States for a sample of weekly observations which spans the period from June 1996 to August 2011. The result indicate the common perception that less competitive gasoline markets exhibit price asymmetry, while highly competitive gasoline market follow a symmetric price adjustment path. In addition, the inclusion of (VAT and excise tax) into retail gasoline prices, supports the existence of price asymmetry in many European countries. Polemis and Fotis (2015) analyzed the asymmetric price adjustment in the five EU countries by examining the impulse response functions of pre and post tax retail prices to a one standard deviation shock in crude oil prices. The estimation results indicate that pre-tax prices tend to respond faster to an increase in crude oil prices than the final gasoline prices. In addition, the response difference becomes statistically insignificant as the retail price adjustment goes into the fifth week and beyond. This pattern suggests a rent-seeking oligopolistic behavior by the marketers. The study concluded that the oligopolistic structure of the local gasoline markets along with crude oil volatility triggers price asymmetric 
adjustment path.

This study is consistent with Greenwood Nimmo and Shin (2013, henceforth GS13) and sheds more light on how the manipulation of the tax system by retailers can be used to obscure asymmetry at the pump. Revisiting the wholesale and retail gasoline price adjustments to fluctuations in the input cost prices for a monthly panel dataset of 48 US states over the period 1994 to 2011, Polemis and Tsionas (2016) employed for the first time in the empirical literature nonlinear semiparametric models with local Generalized Method of Moments (GMM) estimators. The findings indicate that wholesale and retail gasoline prices adjust more rapidly in an upward than a downward direction, confirming the rockets and feathers hypothesis. Karagidnnis, Panagopoulus and Vlamis (2015) examined whether crude oil prices are transmitted to the retail gasoline prices in the short and long-run, and tested the symmetry of price adjustment hypothesis. France, Italy and Spain were studied using Error Correction Models, which account for possible asymmetric adjustment behavior. The results show that rigidities in the transmission process exist but the retail fuel speed of upward/downward as symmetric in all four economies analyzed. Thus, the findings on the whole do not provide firm evidence to support the rockets and feathers hypothesis.

The focus of this study is the Italian domestic heating oil market, which has largely been left behind in the extant literature. This study is further motivated by the concerns that the recent tumbling in oil prices which began in 2013 may not be reflecting in this market owing to the oil-deficient status of Italy, thereby leading to asymmetric price adjustment in this market.

\section{Data and methodology}

Monthly time series observations for the period January 2005 to December 2015 (a total of 132 observations) constitute the data for this paper. The retail prices of domestic heating oil at pump (i.e inclusive of tax and duty) and exclusive of tax and duty (i.e ex-tax prices) together with the cost of imported crude oil in Italy constitute the variables of interest. The data were sourced from the International Energy Agency (IEA) monthly oil price statistics. This study used crude oil cost for Italy measured in dollars per barrel and the retail prices of domestic heating oil that is measured in the national currency of Italy converted to US dollars using the exchange rate data obtained from OECD statistics (Monthly Monetary and Financial Statistics, MEI) in order to effectively track the asymmetry in the response of the retail price of domestic heating oil to changes in the crude oil costs. The entire dataset was indexed to year 2010 (i.e. $2010 \mathrm{Y}=100 \%$ ). Thereafter, the data was logged prior to estimation. Figure 1 plots the data using its indexed representation. This figure indicates that the prices track themselves closely, thereby suggesting that the relationship between them might be symmetric rather than asymmetric. The plots also suggest that a stable equilibrium relationship may be existing between the prices. This study will investigate this relationship as part of the empirical analysis.

Figure 1: Time series plot of the data

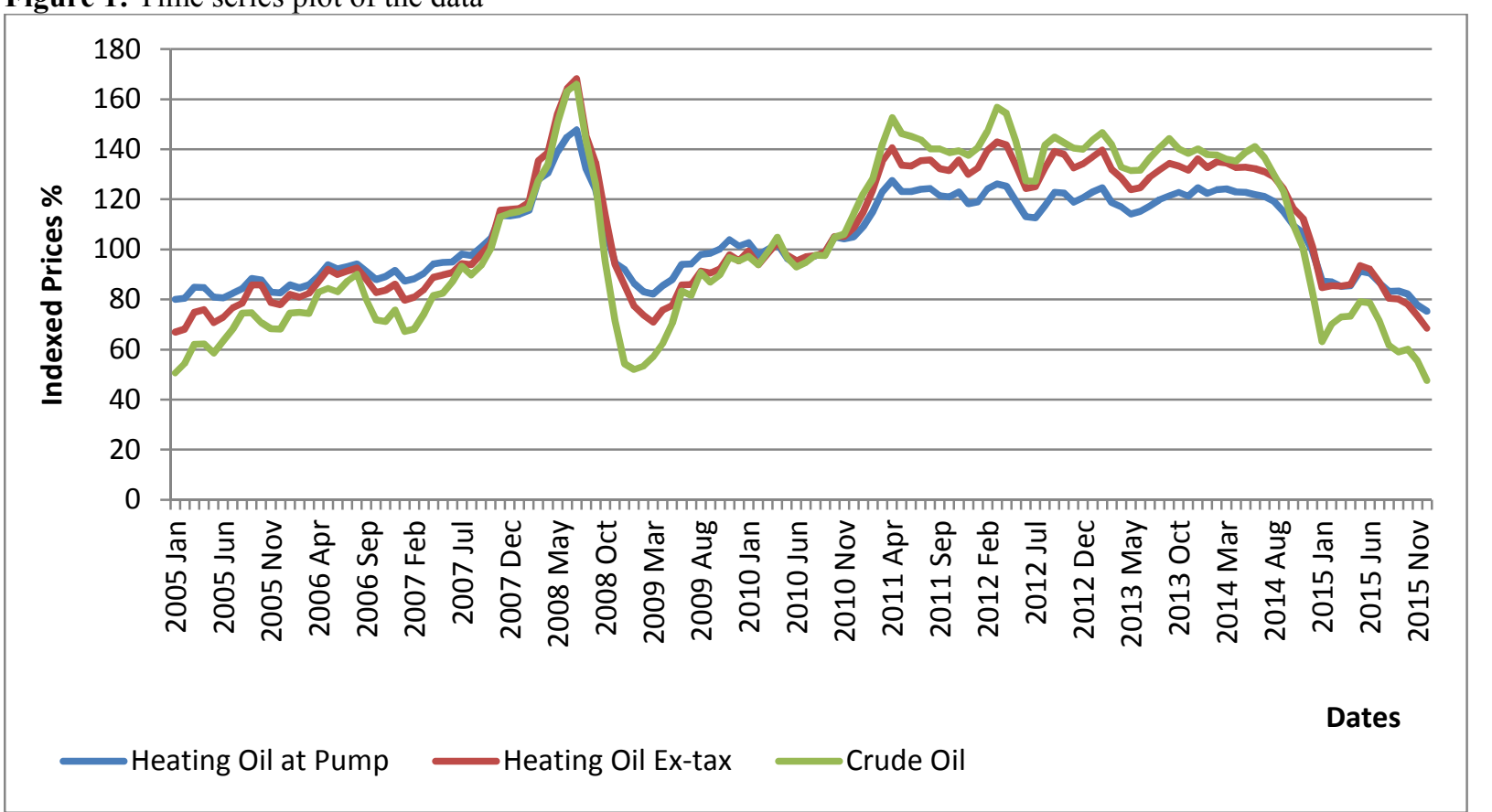

Source: Authors. Note: The domestic heating oil prices at pump include tax and duty while the Ex-tax prices exclude tax and duty.

The study adopted the econometric framework applied by GS13 in modeling the asymmetric price 
transmission in the UK retail energy sector, which was initially advanced by Shin, Yu and Greenwood-Nimmo (2013) for modeling asymmetric cointegration and dynamic multipliers in a non-linear autoregressive distributed lag (NARDL) framework. Under this framework, short-run and long-run non-linearities were introduced through positive and negative partial sum decompositions of the explanatory variables. In the empirical literature, Webber (2000), Lee (2000), Viren (2001), Bachmeier and Griffin (2003), and BCG, among others, applied partial sum decompositions to the analysis of dynamic asymmetry with great success.

The framework is built around the asymmetric cointegrating relationship of the form:

$$
Y_{t}=\theta^{+} X_{t}^{+}+\theta^{-} X^{-}+u_{t}
$$

Where $Y_{t}$ is an I(1) variable, and the explanatory variable is decomposed as follows:-

$$
X_{t}=X_{0}+X_{t}^{+}+X_{t}^{-}
$$

Where $X_{t}^{+}=\sum_{j=1}^{t} \max \left(\Delta \mathrm{X}_{\mathrm{j}}, 0\right)$ and $X_{t}^{-}=\sum_{j=1}^{t} \min \left(\Delta \mathrm{X}_{\mathrm{j}}, 0\right)$ are partial sum processes of positive and negative changes in $X_{t}$, while $X_{0}$ is an initial threshold value that is assumed to be zero following Shin, $\mathrm{Yu}$ and Greenwood-Nimmo (2013). $\Delta$ is the first difference operator while $\theta^{+}$and $\theta^{-}$are the associated asymmetric long-run parameters. The NARDL $(p, q)$ model associated with equation (1) can be written in its level form as follows:

$$
Y_{t}=\sum_{j=1}^{P} \phi_{\mathrm{j}} \mathrm{Y}_{\mathrm{t}}-\mathrm{j}+\sum_{j=O}^{q}\left(\theta_{\mathrm{j}}^{+} X_{t-j}^{+}+\theta_{j}^{-} X_{t-j}^{-}\right)+\varepsilon_{\mathrm{t}}
$$

The underlying model in this study is derived from equation (3) following Shin, Yu and Greenwood-Nimmo (2013). This is specified in its error correction form as follows:

$$
\begin{aligned}
& \Delta \mathrm{Y}_{\mathrm{t}}=\rho \mathrm{Y}_{\mathrm{t}-1}+\theta^{+} X_{t-1}^{+}+\theta^{-} X_{t-1}^{-}+\sum_{j=1}^{p-1} \phi_{\mathrm{j}} \Delta \mathrm{Y}_{\mathrm{t}-1}+\sum_{j=O}^{q-1}\left(\Omega_{j}^{+1} \Delta X_{t=1}^{-}+\Omega_{j}^{+1} \Delta X_{t-1}^{-}\right)
\end{aligned}
$$

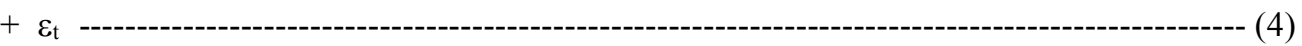

Where $\rho$ is the speed of adjustment while $\beta^{+}=\frac{-\theta^{+}}{\rho}$ and $\beta^{-}=\frac{-\theta^{-}}{\rho}$ are the asymmetric long-run parameters.

In the above specifications, $\mathrm{Y}_{\mathrm{t}}$ captures the retail price of domestic heating oil in Italy, while $\mathrm{X}_{\mathrm{t}}$ captures the crude oil costs for Italy. To ascertain the orders of integration of the variables in this study, the ADF unit root tests were used. This is to ensure that they are consistent with the underlying requirements of the nonlinear ARDL framework. The result of cointegration tests based on the bounds testing approach of Pesaran, Smith and Shin 2001 (henceforth PSS) and the t-BDM statistic of Banerjee et al (1998) are also reported in this study.

\section{Empirical results and discussion}

We began this empirical analysis by examining the time series properties of the data. To do this, we performed the ADF unit root test on all the variables. The results are reported in Table 1. The results indicate that all the variables are integrated of order one, I(1), which is consistent with the underlying assumptions of our model. These results suggest that the variables may be cointegrated. Thus, we include cointegration analysis as part of the nonlinear ARDL estimation results based on the bounds testing procedure of PSS and the t-BDM statistic of Banerjee et al (1998).

Table 1: Unit Root Test Results

\begin{tabular}{|l|l|l|l|l|}
\hline Variables & $\mathbf{5 \%}$ Critical Value & $\begin{array}{l}\text { ADF Test Stat at } \\
\text { Levels }\end{array}$ & $\begin{array}{l}\text { ADF Test Stat at } \\
\mathbf{1}^{\text {st }} \text { Difference }\end{array}$ & $\begin{array}{l}\text { Order } \\
\text { Integration }\end{array}$ \\
\hline $\begin{array}{l}\text { Domestic Heating } \\
\text { Oil at Pump }\end{array}$ & -3.445 & -1.601 & $-7.311^{*}$ & $\mathrm{I}(1)$ \\
\hline $\begin{array}{l}\text { Domestic Heating } \\
\text { Oil Ex-Tax }\end{array}$ & -3.445 & -1.558 & $-7.217^{*}$ & $\mathrm{I}(1)$ \\
\hline Crude Oil & -3.445 & -1.635 & $-6.367^{*}$ & $\mathrm{I}(1)$ \\
\hline
\end{tabular}

Source: Authors. Notes: Domestic heating oil at pump is inclusive of tax and duty while Domestic heating oil extax is exclusive of tax and duty. *denotes significance at $5 \%$ level.

The results of the non-linear ARDL model estimation for this study are reported in Table 2 . This model shows the transmission of changes in crude oil costs to Italian ex-tax and pump prices of retail domestic heating oil. The results show that for both the pump price and the ex-tax price, the speed of adjustment is $17 \%$ per month. This is quite sluggish and consistent with GS13, which explained that sluggish speed of adjustment is typical of markets witnessing weak competition and prolonged periods of mispricing. This is also consistent with the fact that Italy is an oil-deficient economy. 
The results in Table 2 further indicate the absence of long-run asymmetry even at the $10 \%$ level for both the ex-tax prices and the pump prices of retail domestic heating oil in Italy. However, the long-run coefficient of 0.53 at pump is smaller than the corresponding value of 0.74 for ex-tax prices, showing that consumers at pump are more prone to the vagaries of the international oil market. Nonetheless, the absence of long-run asymmetry also indicates that the market is free from long-run rent-seeking. There is absence of rent-seeking behavior in the domestic heating oil market suggests that the product has an elastic demand.

Table 2: NARDL Estimation Results

\begin{tabular}{|l|l|l|}
\hline & Ex-tax Heating Oil Prices & Heating Oil Pump Prices \\
\hline Estimated Coefficients & & \\
\hline$\rho$ & $-0.17^{* * *}$ & $-0.17^{* * *}$ \\
\hline$\beta^{+}$ & $0.74^{* * *}$ & $0.53^{* * *}$ \\
\hline$\beta^{q-1} \pi_{j}^{+}$ & $0.74^{* * *}$ & $0.53^{* * *}$ \\
\hline$\sum_{j=1}^{q-1} \pi_{j}^{-}$ & $0.69^{* * *}$ & $0.62^{* *}$ \\
\hline Symmetry Tests $_{j=1}$ & $0.62^{* * *}$ & $0.38^{* *}$ \\
\hline $\mathcal{H}_{0}: \beta^{+}=\beta^{-}$ & & \\
\hline $\mathcal{H}_{0}: \sum_{j=1}^{q-1} \pi_{j}^{+}=\sum_{j=1}^{q-1} \pi_{j}^{-}$ & 0.06 & 0.18 \\
\hline Diagnostics & 0.42 & $4.26 * *$ \\
\hline $\mathrm{F}_{\mathrm{PSS}}$ & & \\
\hline $\mathrm{t}_{\mathrm{BDM}}$ & 3.65 & 3.92 \\
\hline $\mathrm{BG}$ Test $\left(\mathrm{NR}^{2}\right)$ & $-3.31^{* *}$ & $-3.42^{* *}$ \\
\hline ARCH Test & 4.97 & 4.73 \\
\hline$\overline{\mathcal{R}}^{2}$ & $24.76^{* *}$ & 17.48 \\
\hline
\end{tabular}

Source: Authors. Notes: The notation for the estimated coefficients relates to the NARDL model of equation (4). The reported symmetry tests are standard Wald tests. The BG Test is the Breusch-Godfrey serial correlation test, while the ARCH Test is the standard Heteroskedasticity Test. The BG Test and the ARCH Test were conducted at lag 12, since the dataset comprises monthly series. The relevant $\mathrm{k}=1$ critical values reported by PSS for the $\mathrm{t}_{\mathrm{BDM}}$ statistic are $-2.91,-3.22$, and -3.82 at the $10 \%, 5 \%$ and $1 \%$ levels. The equivalent critical values for the $\mathrm{F}_{\mathrm{PSS}}$ statistic are 4.78, 5.73 and 7.84. * denotes Significance at the $10 \%$ level; ** denotes Significance at the $5 \%$ level; *** denotes Significance at the $1 \%$ level.

The results also indicate significant evidence of short-run additive asymmetry only in the pump prices at the $5 \%$ level. The results indicate that crude oil price increases are passed through more strongly and rapidly than price decreases in the periods immediately following the shocks. This is because the sum of the estimated positive shortrun parameters which is 0.62 is higher than the corresponding sum of the negative short-run parameters which is 0.38. Indeed, these results provide clear evidence of the prevalence of the rockets and feathers effect in the Italian retail domestic heating oil market. However, the results do not provide any evidence of rent-seeking since asymmetry is not obscured at pump. Nonetheless, the prevalence of rockets and feathers effect at pump is consistent with the reality of the Italian oil industry which shows that the Eni brand holds a dominant status, which makes the market prone to less competition and collusive behavior. Thus, there is need for vigilance by the regulators in this market to preserve competition and the overall social welfare.

The diagnostic checks in Table 2 indicate that the assumptions of the underlying model have been sufficiently satisfied. The tBDM-statistics of Banerjee et al 1998 indicate a stable long-run relationship between variables at the 5\% level. The Breusch - Godfrey serial correlation tests indicate the absence of auto-correlation problem in all cases. However, the problem of heteroscedasticity is found at the 5\% level. Interestingly, the standard errors of the estimates thus obtained after applying the Newey-West HAC method to correct the problem did not differ materially from those obtained without correcting for heteroscedasticity. Lastly, the adjusted $\mathrm{R}^{2}$, which has the values of $78 \%$ and $84 \%$ indicate that changes in crude oil costs account substantially for variations in the retail domestic heating oil prices in Italy, which is consistent with economic expectations.

\section{Conclusion and Policy Implications}

This paper studied the Italian domestic heating oil market for evidence of asymmetric price adjustment and rentseeking following changes in crude oil costs. Nonlinear autoregressive distributed Lag (NARDL) modeling framework was applied. The study used monthly time series data for the period January 2005 to December 2015. The findings reveal that the speed with which Italian domestic heating oil adjusts to changes in crude oil cost was 
very sluggish. The results further indicate the presence of short-run additive asymmetry at $5 \%$ level at pump, which is consistent with the rockets and feathers effect. However, the results did not show any evidence of long-run asymmetry or long-run rent-seeking. Even in the short-run, the results did not reveal any evidence of rent-seeking. Overall, the study concludes that the presence of sluggish speed of adjustment and rockets and feathers effect in the pump prices raise serious anti-trust issues. Accordingly, the study recommends that the market should be continuously monitored so that the dominant status of retailers such as the Eni brand is not abused, thereby leading to less competition and collusive behaviours.

\section{References}

Asplund, M., Eriksson, R., and R. Friberg (2000). Price Adjustment by a Gasoline Retail Chain. The Scandinavian Journal of Economics 102, 101-121.

Bachmeier, L. J. and J. M. Griffin (2003). New Evidence on Asymmetric Gasoline Price Responses. The Review of Economics and Statistics 85(3), 772-776.

Bacon, R.W. (1991). Rockets and Feathers: The Asymmetric Speed of Adjustment of UK Retail Gasoline Prices to Cost Changes. Energy Economics 13, 211-218.

Balke, N.S., Brown, S.P. and M. K. Yücel (1998). Crude Oil and Gasoline Prices: An Asymmetric Relationship? Federal Reserve Bank of Dallas Economic and Financial Policy Review Q1, 2-11.

Banerjee, A., Dolado, J. and R. Mestre (1998). Error-correction Mechanism Tests for Cointegration in a Singleequation Framework. J. Time Ser. Anal. 19, 267-283.

Borenstein, S., Cameron, A.C. and R. Gilbert (1997). Do Gasoline Prices Respond Asymmetrically to Crude Oil Prices? Quarterly Journal of Economics 112, 305-339.

Chacra, M. (2002). Oil-Price Shocks and Retail Energy Prices in Canada. Working Paper 2002-38, Bank of Canada.

Greenwood-Nimmo, M. and Y. Shin (2013). Taxation and the Asymmetric Adjustment of Selected Retail Energy Prices in the UK. Economics Letters 121, 411-416.

Karagiannis, S., Panagopoulos, Y. and P. Vlamis (2015). Are unleaded gasoline and diesel price adjustments symmetric? A comparison of the four largest EU retail fuel markets. Economic Modelling, 48(C), 281 - 291.

Karrenbrock, J. D. (1991). The Behavior of Retail Gasoline Prices: Symmetric or Not? Federal Reserve Bank of St. Louis, July/August, $19-29$.

Lee, J. (2000). The Robustness of Okun's Law: Evidence from OECD Countries. Journal of Macroeconomics 22, $331-56$.

Manning, D. N. (1991). Petrol Prices, Oil Price Rises and Oil Price Falls: Some Evidence for the UK since 1972. Applied Economics 23, 1535 - 1541.

Monopolies and Mergers Commission (MMC) (1965). Report on the Supply of Petrol to Retailers in the United Kingdom, HMSO, London.

Monopolies and Mergers Commission (MMC) (1979). Report on the Supply of Petrol in the United Kingdom by Wholesale, HMSO, London.

Monopolies and Mergers Commission (MMC) (1990). The Supply of Petrol, HMSO, London.

Pesaran, M.H., Smith, R.J. and Y. Shin (2001). Bounds Testing Approaches to the Analysis of Level Relationships. Journal of Applied Econometrics 16, 289-326.

Polemis, M. L. and P. N. Fotis (2014). The taxation effect on gasoline price asymmetry nexus: Evidence from both sides of the Atlantic. Energy Policy 73, 225 - 233.

Polemis, M. L. and P. N. Fotis (2015). Rent seeking oligopolistic behaviour in European gasoline markets. Economics Bulletin 35(1), 827 - 833.

Polemis, M. L. and M. G. Tsionas (2016). An alternative semiparametric approach to the modelling of asymmetric gasoline price adjustment. Energy Economics 56, 384 - 388.

Reilly, B. and R. Witt (1998). Petrol Price Asymmetries Revisited. Energy Economics 20, 297-308.

Shin, Y., Yu, B. and M. J. Greenwood-Nimmo (2013). Modelling Asymmetric Cointegration and Dynamic Multipliers in a Nonlinear ARDL framework, in: Horrace, W. C. and Sickles, R. C., eds., Festschrift in Honor of Peter Schmidt: Econometric Methods and Applications, Springer Science \& Business Media, New York.

Viren, M. (2001). The Okun Curve is Non-linear. Economics Letters 70, 253-57.

Webber, A.G. (2000). Newton's Gravity Law and Import Prices in the Asia Pacific. Japan and the World Economy 12, 71-87. 